\title{
Pemilihan Kelurahan Terbaik di Kecamatan Palmerah Menggunakan Metode Analitycal Hierarchi Process
}

\author{
Samsiyatun ${ }^{1}$, Yunita $^{2}$, Agus Junaidi ${ }^{3}$ \\ 1,2Sistem Informasi, STMIK Nusa Mandiri

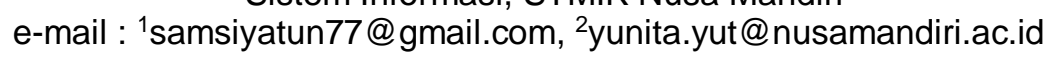 \\ ${ }^{3}$ Teknologi Informasi, Universitas Bina Sarana Informatika \\ e-mail: agus.asj@bsi.ac.id
}

\begin{abstract}
Abstrak
Dalam mewujudkan kelurahan terbaik perlu dilakukan dengan cara gotong royong masyarakat dikelurahan, sehingga dapat menilai keberhasilan dalam pembangunan kelurahan, dan perlu dilakukan penilaian secara merata, terarah dan terkoordinasi untuk mendukung rencana pemerintahan yang baik, maka dilakukan kegiatan pelaksanaan penilaian kelurahan terbaik, sesuai dengan indikator penilaian. Dalam penilaian kelurahan terbaik dilakukan dengan cara membandingkan perkembangan terbaru berdasarkan data profil kelurahan sesuai dengan indikator penilaian yang sudah ditentukan. Penelitian ini bertujuan membangun sebuah sistem pendukung keputusan untuk menentukan kelurahan terbaik berdasarkan skor penilaian dengan menggunakan metode Analytical Hierarchi Process (AHP). Penilaian kelurahan terbaik terdiri dari 6 Alternatif yaitu Kelurahan Jatipulo, Kemanggisan, Kota Bambu Selatan, Kota Bambu Utara, Palmerah dan Slipi. Hasil dari sistem ini berupa rangking setiap kelurahan yang telah dinilai sehingga menghasilkan rekomendasi untuk pengambilan keputusan dalam menetukan kelurahan terbaik. Nilai total paling tinggi digunakan untuk merangking kelurahan terbaik yaitu Kelurahan Kemanggisan dengan Hasil Akhir 0,190.
\end{abstract}

Kata Kunci : Analytical Hierarchi Process, Kelurahan terbaik, Rangking

\begin{abstract}
In realizing the best kelurahan needs to be done in a way of mutual cooperation community in the village, so that it can assess the success in the development of kelurahan, and needs to be assessed equally, directed and coordinated to support a good governance plan, then the implementation of the best village assessment activities, according to the assessment. In the assessment of the best kelurahan, it is done by comparing the latest developments based on kelurahan profile data in accordance with predetermined assessment indicators. This study aims to build a decision support system to determine the best kelurahan based on an assessment score using the Analytical Hierarchy Process (AHP) method. The assessment of the best villages consists of 6 Alternative, namely Jatipulo Village, Kemanggisan, Kota Bambu Selatan, Kota Bambu Utara, Palmerah and Slipi. The results of this system are in the form of ranking each village that has been assessed so as to produce recommendations for decision making in determining the best village. The highest total value is used to rank the best kelurahan, Kelurahan Kemanggisan with a Final Result of 0,190.
\end{abstract}

\section{Keywords: Analytical Hierarchi Process, the best village, ranking}

\section{Pendahuluan}

Kecamatan dan Kelurahan merupakan salah satu lembaga yang mempunyai peranan penting dalam pemerintahan dan penyelenggaraan administrasi kemasyarakatan (Faza Alameka, Aulia Rahman, 2016). Kelurahan adalah pembagian wilayah administratif di Indonesia di bawah Kecamatan dalam konteks otonomi daerah di Indonesia. Kelurahan merupakan wilayah kerja Lurah sebagai Perangkat Daerah Kabupaten atau kota Kelurahan dipimpin oleh seorang Lurah yang berstatus sebagai Pegawai Negeri Sipil dan Kelurahan memiliki hak mengatur wilayahnya lebih terbatas (Robial2, 2015). Kelurahan merupakan suatu instansi pemerintah terkecil yang berhubungan langsung dengan masyarakat dalam hal 
memberikan jasa pelayanan administrasi kependudukan. Kesibukkan dan rutinitas masyarakat yang sangat tinggi menyebabkan masyarakat sangat mengharapkan pelayanan administrasi kependudukan yang cepat, akurat dan efisien dalam melayani kebutuhan masyarkatnya.(Muhammad \& Bahar, 2016).

Kecamatan Palmerah merupakan salah satu dari 8 Kecamatan dalam wilayah kerja kota Jakarta Barat. Jumlah Kelurahan dalam Kecamatan Palmerah terdiri dari 6 Kelurahan yaitu Kelurahan Jatipulo, Kemanggisan, Kota Bambu Selatan, Kota Bambu Utara, Palmerah dan Slipi. Kecamatan Palmerah mempunyai visi untuk mewujudkan pelayanan publik yang nyaman dan sejahtera. Dalam menciptakan pelayanan yang nyaman dan sejahtera Kecamatan Palmerah juga menggerakan pemerintah Kelurahan yang ada di Kecamatan Palmerah untuk dapat berjalan secara merata dan adanya saling kontrol antara masyarakat dan aparatur pemerintah Kelurahan. Dengan demikian Kecamatan Palmerah juga dapat menilai bagaimana cara kerja pemerintah Kelurahan dalam pemerintahan dan penyelengaraan administrasi masyarakat dengan baik dan Pelayanan Kesehatan terhadap masyarakat. Namun sampai saat ini Kecamatan Palmerah belum memiliki metode khusus dalam pemilihan kelurahan terbaik.

Oleh sebab itu dibutuhkan metode khusu dalam pemilihan kelurahan terbaik agar hasil keputusan bersifat objective. Dalam penelitin ini metode yang digunakan adalah AHP yang merupakan sebuah hierarki fungsional dengan input utamanya persepsi manusia. Keberadaan hierarki memungkinkan dipecahkan masalah kompleks atau tidak terstruktur dalam subsub masalah, lalu menyusunnya menjadi suatu bentuk hierarki.(Pratiwi, Sitio, \& Sindar, 2018)

\section{Metode Penelitian}

Metode dalam pengumpulan data yang digunakan pada penelitian ini adalah:

1.Observasi

Pada tahap inidilakukan observasi yang bertujuan untuk memperoleh data secara langsung dari Kecamatan Palmerah dan Kelurahan - kelurahan yang ada di Kecamatan Palmerah yaitu Kelurahan Jatipulo, Kemanggisan, Kota Bambu
Selatan, Kota Bambu Utara, Palmerah dan Slipi

2. Wawancara

Wawancara adalah merupakan Teknik pengumpulan data yang secara langsung dengan melakukan tanya jawab kepada pihak-pihak yang terkait yang dapat memberikan penjelasan mengenai Pemilihan Kelurahan Terbaik di Kecamatan Palmerah.

3. Studi Pustaka

Mengumpulkan data- data, yaitu yang bersumber dari berbagai buku karya ilmiah sesuai dengan pokok pembahasan baik dari text book maupun internet.

4. Kuesioner

Dalam Teknik ini para responden diberikan kesempatan untuk mengisi angket dengan jawaban yang sudah tersedia. Dengan demikian, jawaban bersifat tertutup. Pada Teknik ini angket diberikan kepada beberapa masyarakat di setiap kelurahan yang menjadi obyek penelitian.

\section{Metode Analisis Data}

Berdasarkan dari tujuan penelitian ini yaitu untuk menghasilkan sebuah keputusan dalam pemilihan kelurahan terbaik di Kecamatan Palmerah. Maka secara umum analisis yang digunakan terdiri dari beberapa kriteria yang dapat menentukan Kelurahan terbaik di Kecamatan Palmerah. kemudian data dihitung manual dengan menggunakan Microsoft Excel. Adapun kriteria yang digunakan dalam menentukan kelurahan terbaik di Kecamatan Palmerah yaitu :

\section{A. Pelayanan Kesehatan}

Pelayanan kesehatan menjadi pokok pertama dalam penilaian terhadap kelurahan terbaik sehingga kita dapat mengetahui bagaimana tindakan pemerintah dalam memberikan pelayanan kesehatan terhadap masyarakatnya. Didalam Pelayanan kesehatan ada 4 kriteria penilaian yaitu :

\section{Fasilitas Kesehatan}

Persediaan fasilitas kesehatan terhadap masyarakat yaitu seperti Rumah sakit, Klinik, Puskesmas, Apotik, Peralatan kesehatan dan sebagainya.

\section{Kegiatan Posyandu}

Pelaksanaan dan pelayanan dalam kegiatan posyandu terhadap masyarakat. 


\section{Program KB}

Dalam mewujudkan keluarga yang sejahtera salah satunya dengan program keluarga berencana (KB) sesuai dengan Undang-undang Nomor 10 Tahun 1992 Tentang perkembangan kependudukan dan pembangunan keluarga sejahtera.

\section{Jaminan Kesehatan}

Tindakan yang dilakukan pemerintah dalam menghadapi masyarakat yang kurang mampu dan jaminan kesehatan terhadap masyarakatnya.

\section{Hasil dan Pembahasan}

\section{Matrik Perbandingan}

Setelah menentukan kriteria dalam program Sistem Pendukung Keputusan Pemilihan Kelurahan Terbaik di Tingkat Kecamatan maka langkah selanjutnya dalam pemilihan Kelurahan terbaik yaitu membuat matriks perbandingan berpasangan yang menggambarkan kontribusi relatif atau pengaruh setiap elemen terhadap masingmasing kriteria dengan kriteria lainnya.

Tabel 1. Skala Penilaian Perbandingan Berpasangan

\begin{tabular}{|c|l|}
\hline $\begin{array}{c}\text { Intensitas } \\
\text { Kepenting } \\
\text { an }\end{array}$ & \multicolumn{1}{|c|}{ Keterangan } \\
\hline 1 & Kedua elemen sama pentingnya \\
\hline 3 & $\begin{array}{l}\text { Elemen yang satu sedikit lebih penting } \\
\text { daripada elemen yang lainnya }\end{array}$ \\
\hline 5 & $\begin{array}{l}\text { Elemen yang satu lebih penting dari } \\
\text { pada yang lainnya }\end{array}$ \\
\hline 7 & $\begin{array}{l}\text { Satu elemen jelas lebih mutlak } \\
\text { penting dari pada elemen lainnya }\end{array}$ \\
\hline 9 & $\begin{array}{l}\text { Satu elemen mutlak penting dari pada } \\
\text { elemen lainnya }\end{array}$ \\
\hline $2,4,6,8$ & $\begin{array}{l}\text { Nilai-nilai antara dua nilai } \\
\text { pertimbangan-pertimbangan yang } \\
\text { berdekatan }\end{array}$ \\
\hline
\end{tabular}

Perhitungan konsistensi logis dengan mengalikan matriks dengan prioritas bersesuaian :

1. Menjumlahkan hasil kali per baris

2. Hasil penjumlahan tiap baris dibagi prioritas bersangkutan dan hasilnya dijumlahkan

3. Hasil poin 2 dibagi jumlah elemen, didapatkan $\lambda$ Maks.

4. $\mathrm{Cl}=\lambda \frac{\text { Maks-n }}{n-1}$ $\mathrm{n}-1$

5. Index Konsistensi

$$
\mathrm{CR}=\frac{\mathrm{Cl}}{\mathrm{RI}}
$$

6. Rasio konsistensi, RI : indeks random konsistensi. Jika rasio konsistensi $\leq 0.1$, hsil perhitungan data dapat dilihat pada tabel,

Tabel 2. Daftar Indeks Random Konsistensi

\begin{tabular}{|c|c|}
\hline $\begin{array}{c}\text { Ukuran Matrik } \\
1,2\end{array}$ & Nilai \\
0,00 \\
\hline 3 & 0,58 \\
\hline 4 & 0,90 \\
\hline 5 & 1,12 \\
\hline 6 & 1,14 \\
\hline 7 & 1,32 \\
\hline 8 & 1,41 \\
\hline 9 & 1,45 \\
\hline 10 & 1,49 \\
\hline 11 & 1,51 \\
\hline 12 & 1,48 \\
\hline 13 & 1,56 \\
\hline 14 & 1,57 \\
\hline 15 & 1,59 \\
\hline
\end{tabular}

Tabel 3. Matrik Perbandingan Berpasangan Berdasarkan Kriteria

\begin{tabular}{|l|c|c|c|c|}
\hline \multicolumn{1}{|c|}{ Goal } & $\begin{array}{c}\text { Fasilit } \\
\text { as } \\
\text { Keseh } \\
\text { tan }\end{array}$ & $\begin{array}{c}\text { Kegiat } \\
\text { an } \\
\text { Posya } \\
\text { ndu }\end{array}$ & $\begin{array}{c}\text { Progr } \\
\text { am } \\
\text { KB }\end{array}$ & $\begin{array}{c}\text { Jamina } \\
\mathbf{n} \\
\text { Keseha } \\
\text { tan }\end{array}$ \\
\hline $\begin{array}{l}\text { Fasilita } \\
\text { s } \\
\text { Keseha } \\
\text { tan }\end{array}$ & 1 & $3 / 1$ & $3 / 2$ & $3 / 4$ \\
\hline $\begin{array}{l}\text { Kegiata } \\
\text { n } \\
\text { Posyan } \\
\text { du }\end{array}$ & $1 / 3$ & 1 & $1 / 2$ & $1 / 4$ \\
\hline $\begin{array}{l}\text { Progra } \\
\text { m KB }\end{array}$ & $2 / 3$ & $2 / 1$ & 1 & $1 / 2$ \\
\hline $\begin{array}{l}\text { Jamina } \\
\mathbf{n}\end{array}$ & $4 / 3$ & $4 / 1$ & $2 / 1$ & 1 \\
$\begin{array}{l}\text { Keseha } \\
\text { tan }\end{array}$ & & & & \\
\hline
\end{tabular}


Tabel 4. Matrik Perbandingan Berpasangan Berdasarkan Kriteria Yang Dinormalkan

\begin{tabular}{|c|c|c|c|c|c|c|c|}
\hline $\begin{array}{c}\text { Goa } \\
\text { I }\end{array}$ & $\begin{array}{c}\text { Fas } \\
\text { ilita } \\
\text { s } \\
\text { Kes } \\
\text { eht } \\
\text { an }\end{array}$ & $\begin{array}{c}\text { Keg } \\
\text { iata } \\
n \\
\text { Pos } \\
\text { yan } \\
\text { du }\end{array}$ & $\begin{array}{c}\text { Pro } \\
\text { gra } \\
\text { m } \\
\text { KB }\end{array}$ & $\begin{array}{c}\text { Jam } \\
\text { inan } \\
\text { Kes } \\
\text { ehat } \\
\text { an }\end{array}$ & $\begin{array}{l}\mathrm{Ju} \\
\mathrm{ml} \\
\mathrm{ah}\end{array}$ & $\begin{array}{l}\mathrm{R} \\
\text { at } \\
\text { a- } \\
\text { ra } \\
\text { ta }\end{array}$ & $\begin{array}{l}\text { Pri } \\
\text { orit } \\
\text { as }\end{array}$ \\
\hline $\begin{array}{l}\text { Fasi } \\
\text { litas } \\
\text { Kes } \\
\text { ehat } \\
\text { an }\end{array}$ & $\begin{array}{c}0,3 \\
00\end{array}$ & $\begin{array}{c}0,3 \\
00\end{array}$ & $\begin{array}{l}0,3 \\
00\end{array}$ & $\begin{array}{c}0,30 \\
0\end{array}$ & $\begin{array}{c}1, \\
20 \\
0\end{array}$ & $\begin{array}{l}0, \\
3 \\
0 \\
0\end{array}$ & $\begin{array}{c}40 \\
0\end{array}$ \\
\hline $\begin{array}{l}\text { Keg } \\
\text { iata } \\
\text { n } \\
\text { Pos } \\
\text { yan } \\
\text { du }\end{array}$ & $\begin{array}{l}0,1 \\
00\end{array}$ & $\begin{array}{l}0,1 \\
00\end{array}$ & $\begin{array}{l}0,1 \\
00\end{array}$ & $\begin{array}{c}0,10 \\
0\end{array}$ & $\begin{array}{c}0, \\
40 \\
0\end{array}$ & $\begin{array}{l}0 \\
1 \\
0 \\
0\end{array}$ & $\begin{array}{c}40 \\
0\end{array}$ \\
\hline $\begin{array}{l}\text { Pro } \\
\text { gra } \\
\mathrm{m} \\
\mathrm{KB}\end{array}$ & $\begin{array}{c}0,2 \\
00\end{array}$ & $\begin{array}{c}0,2 \\
00\end{array}$ & $\begin{array}{c}0,2 \\
00\end{array}$ & $\begin{array}{c}0,20 \\
0\end{array}$ & $\begin{array}{c}0, \\
80 \\
0\end{array}$ & $\begin{array}{l}0, \\
2 \\
0 \\
0\end{array}$ & $\begin{array}{c}40 \\
0\end{array}$ \\
\hline $\begin{array}{l}\text { Jam } \\
\text { inan } \\
\text { Kes } \\
\text { ehat } \\
\text { an }\end{array}$ & $\begin{array}{c}0,4 \\
00\end{array}$ & $\begin{array}{c}0,4 \\
00\end{array}$ & $\begin{array}{c}0,4 \\
00\end{array}$ & $\begin{array}{c}0,40 \\
0\end{array}$ & $\begin{array}{c}1, \\
60 \\
0\end{array}$ & $\begin{array}{l}0 \\
4 \\
0 \\
0\end{array}$ & $\begin{array}{c}40 \\
0 \\
\end{array}$ \\
\hline
\end{tabular}

$\left(\begin{array}{cccc}1 & 3 & 1,5 & 0,75 \\ 0,33 & 1 & 0,5 & 0,25 \\ 0,66 & 2 & 1 & 0,50 \\ 1,33 & 4 & 2 & 1\end{array}\right) \times\left(\begin{array}{l}0,30 \\ 0,10 \\ 0,20 \\ 0,40\end{array}\right)=\left(\begin{array}{l}1,200 \\ 0,400 \\ 0.800 \\ 1,600\end{array}\right)$

$\left(\begin{array}{l}1,200 \\ 0,400 \\ 0,800 \\ 1,600\end{array}\right), \quad\left(\begin{array}{l}0,30 \\ 0,10 \\ 0,20 \\ 0,40\end{array}\right)=\left(\begin{array}{l}4,00 \\ 4,00 \\ 4,00 \\ 4,00\end{array}\right)$

Amaks $=\underline{4,00+4,00+4,00+4,00}=4,00$

$\mathrm{Cl}=\frac{\lambda \mathrm{maks}-\mathrm{n}}{\mathrm{n}-1}=\frac{4,00-4}{3}=0$

$$
\mathrm{n}-1
$$

Untuk $\mathrm{n}=4, \mathrm{RI}=0,90$ (Indeks Random Konsistensi), maka :

$\mathrm{CR}=\frac{\mathrm{Cl}}{\mathrm{RI}}=\frac{0}{0,90}=0$
Oleh karena CR 0,1 maka rasio konsistensi dari perhitungan tersebut dapat diterima.

Tabel 5. Matrik Perbandingan Berpasangan Alternatif Berdasarkan Fasilitas Kesehatan

\begin{tabular}{|c|c|c|c|c|c|c|}
\hline $\begin{array}{c}\text { Fasilit } \\
\text { as } \\
\text { Keseh } \\
\text { atan }\end{array}$ & $\begin{array}{c}\mathrm{Ja} \\
\mathrm{ti} \\
\mathrm{P} \\
\mathrm{ul} \\
\mathrm{O}\end{array}$ & $\begin{array}{c}\text { Kot } \\
\mathrm{a} \\
\mathrm{Ba} \\
\mathrm{mb} \\
\mathrm{u} \\
\text { Uta } \\
\mathrm{ra}\end{array}$ & $\begin{array}{l}\text { SI } \\
\text { ipi }\end{array}$ & $\begin{array}{l}\text { Palm } \\
\text { erah }\end{array}$ & $\begin{array}{l}\text { Keman } \\
\text { ggisan }\end{array}$ & $\begin{array}{c}\text { Kot } \\
\mathrm{a} \\
\mathrm{Ba} \\
\mathrm{mb} \\
\mathrm{u} \\
\mathrm{Sel} \\
\mathrm{ata} \\
\mathrm{n}\end{array}$ \\
\hline $\begin{array}{l}\text { Jati } \\
\text { Pulo }\end{array}$ & 1 & $8 / 7$ & $\begin{array}{l}8 / \\
6\end{array}$ & 1 & $8 / 9$ & $8 / 7$ \\
\hline $\begin{array}{l}\text { Kota } \\
\text { Bambu } \\
\text { Utara }\end{array}$ & $\begin{array}{l}7 / \\
8\end{array}$ & 1 & $\begin{array}{l}7 / \\
6\end{array}$ & $7 / 8$ & $7 / 9$ & 1 \\
\hline Slipi & $\begin{array}{l}6 / \\
8\end{array}$ & $6 / 7$ & 1 & $6 / 8$ & $6 / 9$ & $6 / 7$ \\
\hline $\begin{array}{l}\text { Palmer } \\
\text { ah }\end{array}$ & 1 & $8 / 7$ & $\begin{array}{l}8 / \\
6\end{array}$ & 1 & $8 / 9$ & $8 / 7$ \\
\hline $\begin{array}{l}\text { Keman } \\
\text { ggisan }\end{array}$ & $\begin{array}{l}9 / \\
8\end{array}$ & $9 / 7$ & $\begin{array}{c}9 / \\
6\end{array}$ & $9 / 8$ & 1 & $9 / 7$ \\
\hline $\begin{array}{l}\text { Kota } \\
\text { Bambu } \\
\text { Selatan }\end{array}$ & $\begin{array}{l}7 / \\
8\end{array}$ & 1 & $\begin{array}{l}7 / \\
6\end{array}$ & $7 / 8$ & $7 / 9$ & 1 \\
\hline
\end{tabular}

Tabel 6. Matrik Perbandingan Berpasangan Alternatif Berdasarkan Kegiatan Posyandu

\begin{tabular}{|c|c|c|c|c|c|c|}
\hline $\begin{array}{l}\text { Kegiatan } \\
\text { Posyand } \\
\text { u }\end{array}$ & $\begin{array}{c}\text { Jat } \\
\text { i } \\
\text { Pul } \\
0\end{array}$ & \begin{tabular}{|c} 
Kota \\
Bam \\
bu \\
Utar \\
a
\end{tabular} & $\begin{array}{l}\text { Sli } \\
\text { pi }\end{array}$ & $\begin{array}{c}\text { Palme } \\
\text { rah }\end{array}$ & $\begin{array}{c}\text { Kemang } \\
\text { gisan }\end{array}$ & $\begin{array}{c}\text { Kota } \\
\text { Bam } \\
\text { bu } \\
\text { Selat } \\
\text { an }\end{array}$ \\
\hline Jati Pulo & 1 & $8 / 7$ & 1 & $8 / 9$ & $8 / 9$ & $8 / 6$ \\
\hline $\begin{array}{l}\text { Kota } \\
\text { Bambu } \\
\text { Utara }\end{array}$ & 7/8 & 1 & 7/5 & $7 / 9$ & $7 / 9$ & $7 / 6$ \\
\hline Slipi & 1 & $5 / 7$ & 1 & $5 / 9$ & $5 / 9$ & $5 / 6$ \\
\hline $\begin{array}{c}\text { Palmera } \\
\mathrm{h}\end{array}$ & $9 / 8$ & $9 / 7$ & 9/5 & 1 & 9/9 & $9 / 6$ \\
\hline $\begin{array}{c}\text { Kemang } \\
\text { gisan }\end{array}$ & $9 / 8$ & $9 / 7$ & $9 / 5$ & $9 / 9$ & 1 & $9 / 6$ \\
\hline $\begin{array}{l}\text { Kota } \\
\text { Bambu } \\
\text { Selatan }\end{array}$ & $6 / 8$ & $6 / 7$ & $6 / 5$ & $6 / 9$ & $6 / 9$ & 1 \\
\hline
\end{tabular}


JURNAL INFORMATIKA, Vol.7 No.2 September 2020

ISSN: 2355-6579 | E-ISSN: 2528-2247

Tabel 7. Matrik Perbandingan Berpasangan Alternatif Berdasarkan Program KB

\begin{tabular}{|c|c|c|c|c|c|c|}
\hline Program KB & Jati Pulo & $\begin{array}{c}\text { Kota Bambu } \\
\text { Utara }\end{array}$ & Slipi & Palmerah & Kemanggisan & $\begin{array}{c}\text { Kota Bambu } \\
\text { Selatan }\end{array}$ \\
\hline Jati Pulo & 1 & $8 / 6$ & $8 / 7$ & $8 / 7$ & $8 / 8$ & $8 / 6$ \\
\hline $\begin{array}{c}\text { Kota Bambu } \\
\text { Utara }\end{array}$ & $6 / 8$ & 1 & $6 / 7$ & $6 / 7$ & $6 / 8$ & 1 \\
\hline Slipi & $7 / 8$ & $7 / 6$ & 1 & $7 / 7$ & $7 / 8$ & $7 / 6$ \\
\hline Palmerah & $7 / 8$ & $7 / 6$ & $7 / 7$ & 1 & $7 / 8$ & $7 / 6$ \\
\hline Kemanggisan & $8 / 8$ & $8 / 6$ & $8 / 7$ & $8 / 7$ & 1 & $8 / 6$ \\
\hline $\begin{array}{c}\text { Kota Bambu } \\
\text { Selatan }\end{array}$ & $6 / 8$ & 1 & $6 / 7$ & $6 / 7$ & $6 / 8$ & 1 \\
\hline
\end{tabular}

Tabel 8. Matrik Perbandingan Berpasangan Alternatif Berdasarkan Jaminan Kesehatan

\begin{tabular}{|l|c|c|c|c|c|c|}
\hline $\begin{array}{l}\text { Jaminan } \\
\text { Kesehatan }\end{array}$ & Jati Pulo & $\begin{array}{c}\text { Kota Bambu } \\
\text { Utara }\end{array}$ & Slipi & $\begin{array}{c}\text { Pal } \\
\text { merah }\end{array}$ & $\begin{array}{c}\text { Kemang } \\
\text { gisan }\end{array}$ & Kota Bambu Selatan \\
\hline $\begin{array}{l}\text { Jati } \\
\text { Pulo }\end{array}$ & 1 & $8 / 7$ & $8 / 7$ & 1 & 1 & $8 / 7$ \\
\hline $\begin{array}{l}\text { Kota } \\
\text { Bambu } \\
\text { Utara }\end{array}$ & $7 / 8$ & 1 & $7 / 7$ & $7 / 8$ & $7 / 8$ & 1 \\
\hline Slipi & $7 / 8$ & $7 / 7$ & 1 & $7 / 8$ & $7 / 8$ & $7 / 7$ \\
\hline $\begin{array}{l}\text { Pal } \\
\text { merah }\end{array}$ & 1 & $8 / 7$ & $8 / 7$ & 1 & 1 & $8 / 7$ \\
\hline $\begin{array}{l}\text { Kemang } \\
\text { gisan }\end{array}$ & 1 & $8 / 7$ & $8 / 7$ & 1 & 1 & $8 / 7$ \\
\hline $\begin{array}{l}\text { Kota } \\
\text { Bambu Selatan }\end{array}$ & $7 / 8$ & $7 / 7$ & $7 / 7$ & $7 / 8$ & $7 / 8$ & 1 \\
\hline
\end{tabular}

Tabel 10. Perhitungan Hasil Akhir Pengolahan AHP (Analytical Hierarchy Prosess)

\begin{tabular}{|l|c|c|c|c|}
\hline Hasil Akhir & Fasilitas Kesehatan & Kegiatan Posyandu & Program KB & Jaminan Kesehatan \\
\hline & 0,300 & 0,100 & 0,200 & 0,400 \\
\hline $\begin{array}{l}\text { Jati Pulo } \\
\begin{array}{l}\text { Uta Bambu } \\
\text { Utara }\end{array}\end{array}$ & 0,178 & 0,170 & 0,190 & 0,178 \\
\hline Slipi & 0,156 & 0,159 & 0,143 & 0,156 \\
\hline Palmerah & 0,133 & 0,124 & 0,167 & 0,156 \\
\hline Kemanggisan & 0,200 & 0,205 & 0,167 & 0,178 \\
\hline $\begin{array}{l}\text { Kota Bambu } \\
\text { Selatan }\end{array}$ & 0,156 & 0,205 & 0,190 & 0,178 \\
\hline
\end{tabular}

Tabel 11. Hasil Akhir AHP Perangkingan

\begin{tabular}{|l|c|c|c|c|c|c|}
\hline $\begin{array}{l}\text { Hasil } \\
\text { Akhir }\end{array}$ & $\begin{array}{c}\text { Fasilitas } \\
\text { Kesehatan }\end{array}$ & $\begin{array}{c}\text { Kegiatan } \\
\text { Posyandu }\end{array}$ & $\begin{array}{c}\text { Program } \\
\text { KB }\end{array}$ & $\begin{array}{c}\text { Jaminan } \\
\text { Kesehatan }\end{array}$ & Total & Rangking \\
\hline $\begin{array}{l}\text { Kemang } \\
\text { gisan }\end{array}$ & 0,060 & 0,021 & 0,038 & 0,071 & 0,190 & 1 \\
\hline $\begin{array}{l}\text { Jati } \\
\text { Pulo }\end{array}$ & 0,053 & 0,017 & 0,038 & 0,071 & 0,180 & 2 \\
\hline $\begin{array}{l}\text { Pal } \\
\text { merah }\end{array}$ & 0,053 & 0,021 & 0,033 & 0,071 & 0,179 & 3 \\
\hline $\begin{array}{l}\text { Kota } \\
\text { Bambu } \\
\text { Utara }\end{array}$ & 0,047 & 0,016 & 0,029 & 0,062 & 0,154 & 4 \\
\hline $\begin{array}{l}\text { Kota } \\
\text { Bambu Selatan }\end{array}$ & 0,047 & 0,014 & 0,029 & 0,062 & 0,152 & 5 \\
\hline Slipi & 0,040 & 0,012 & 0,033 & 0,062 & 0,148 & 6 \\
\hline
\end{tabular}




\section{Kesimpulan}

Hasil dari penelitian ini dapat diambil kesimpulan bahwa nilai total paling tinggi merupakan dasar untuk merangking kelurahan terbaik yaitu :

a. Kelurahan Kemanggisan memiliki nilai tertinggi dengan nilai akhir : 0,190

b. Kelurahan Jati Pulo memiliki prioritas ke 2 dengan nilai akhir : 0,180

c. Kelurahan Palmerah memiliki prioritas ke 3 dengan nilai akhir : 0,179

d. Kelurahan Kota Bambu Utara memiliki prioritas ke 4 dengan nilai akhir : 0,154

e. Kelurahan Kota Bambu Selatan memiliki prioritas ke 5 dengan nilai akhir $: 0,152$

f. Kelurahan Slipi memiliki prioritas ke 6 dengan nilai akhir : 0,148

Dengan adanya sistem pendukung keputusan AHP dalam pemilihan kelurahan terbaik lebih menghemat waktu dan mengurangi terjadinya kesalahan-kesalahan serta dapat mempercepat proses penilaian untuk menentukan kelurahan terbaik.

\section{Referensi}

Anjarwati, S., \& Kuncoro, E. H. (2016). Sistem Pendukung Keputusan Pemberian Pinjaman Pada Koperasi Unit Desa ( KUD ) Menggunakan The Satisficing Model. Jurnal VOI STMIK Tasikmalaya, 5(1), 46-54.

Darmanto, E., Latifah, N., \& Susanti, N. (2014). Penerapan Metode Ahp (Analythic Hierarchy Process) Untuk Menentukan Kualitas Gula Tumbu. Simetris : Jurnal Teknik Mesin, Elektro Dan IImu Komputer, 5(1), 75. https://doi.org/10.24176/simet.v5i1.13 9

Faza Alameka, Aulia Rahman, R. N. M. (2016). Perancangan e-government pada kecamatan dan kelurahan kota samarinda. Seminar IImu Komputer Dan Teknologi Informasi, 1(1), 14-16.

Herman Firdaus, I., Abdillah, G., Renaldi, F., \& Jenderal Achmad Yani JI, U. (2016). Sistem Pendukung Keputusan Penentuan Karyawan Terbaik Menggunakan Metode Ahp Dan Topsis. Seminar Nasional Teknologi Informasi Dan Komunikasi, 2016(Sentika), 2089-9815.
Marbun, M., \& Sinaga, B. (2018). Sistem Pendukung Keputusan (medan).

Muhammad, B., \& Bahar, A. (2016). Model Aplikasi Sistem Pelayanan Terpadu Pada Kantor Kelurahan. 5(April), 895906.

Nugraha, R., Abdillah, G., \& llyas, R. (2018). Kabupaten Cianjur Menggunakan Metode Analytic. 37-42.

Parhusip, F., Yustika, A., Syahputri, I., Damanik, N. S., \& Solikhun. (2018). SPK : Analisa Metode AHP Pada Guru Berprestasi di SD 095130 Senio Bangun. 3(1), 1-5.

Pratiwi, I. R., Sitio, A. S., \& Sindar, A. (2018). Pemilihan Desa Terbaik Di Kecamatan Pagar Merbau Menggunakan Metode Ahp. 1(November), 59-65.

Robial2, D. F. (2015). PERAN PEMERINTAH KELURAHAN DALAM MEWUJUDKAN KEPEMERINTAHAN YANG BAIK. Ejournal.unsrat.ac.id, $4(2)$.

Rohmah, N. (2019). Pengertian Instrumen Penelitian, Bentuk dan Contohnya.

Sinun, A., Nurajizah, S., \& Atmaja, I. (2018). Sistem Penunjang Keputusan Pemilihan Taxi Online Terbaik Menggunakan Metode Analytical Hierarchy Process. 239-248.

Sugiyono. (2017). Metode Penelitian Kuantitatif, Kualitatif dan $R \& D$.

Susanto, A. (2017). Sistem Informasi Manajemen. Bandung.

Yulia, D., \& Pratita, D. (2014). Sistem Infoprmasi Manajemen (1st ed.). Yogyakarta. 